\title{
Measurement uncertainty challenge
}

\author{
Juris Meija ${ }^{1}$
}

Published online: 20 March 2017

(C) Crown copyright in right of Canada 2017

We would like to invite you to participate in the Analytical Challenge, a series of puzzles to entertain and challenge our readers. This special feature of "Analytical and Bioanalytical Chemistry" $(A B C)$ has established itself as a truly unique quiz series, with a new scientific puzzle published every three months. Readers can access the complete collection of published problems with their solutions on the ABC homepage at http://www.springer.com/abc. Test your knowledge and tease your wits in diverse areas of analytical and bioanalytical chemistry by viewing this collection.

In the present challenge, measurement uncertainty is the top$i c$. And please note that there is a prize to be won (a Springer book of your choice up to a value of $€ 100$ ). Please read on...

\section{Meet the challenge}

Richard is a mint worker, and his job is to assay precious metals. One day he received a new batch of sterling silver that was produced by melting pure silver and pure copper. His task is to analyze this material and report the silver content. Richard had ten nearly identical 1-g pins at his disposal, and he decided to use five of them to determine the amount of silver and the other five to determine the amount of copper. He obtained the following results for each of the pins:

$m(\mathrm{Ag})=0.844 \mathrm{~g}, 0.888 \mathrm{~g}, 0.825 \mathrm{~g}, 0.907 \mathrm{~g}, 0.882 \mathrm{~g}$

$m(\mathrm{Cu})=0.060 \mathrm{~g}, 0.096 \mathrm{~g}, 0.067 \mathrm{~g}, 0.075 \mathrm{~g}, 0.070 \mathrm{~g}$

Juris Meija

juris.meija@nrc-cnrc.gc.ca

1 National Research Council Canada, Measurement Science and Standards, 1200 Montreal Rd. M-12, Ottawa, ON K1A 0R6, Canada
As one can see from these data, the silver measurements show approximately $4 \%$ variability as judged by the relative standard deviations, whereas the copper measurements show 20\% variability. Looking at the silver data, Richard concludes that the sterling silver alloy contains $86.9 \%$ silver, on the basis of the average of the five results, with an expanded uncertainty of $4.2 \%$, which he calculated as $k \cdot s / \sqrt{5}$ [where $s$ is the standard deviation of the silver data and $k$ is the $95 \%$ coverage factor from the Student $t$ distribution with four degrees of freedom, $k=t(97.5 \%, 4)=2.78]$. Because this result, $(86.9 \pm 4.2) \%$, is below the $92.5 \%$ nominal value required for sterling silver, Richard concluded that the silver sample does not meet the $92.5 \%$ purity requirement and has to be rejected.

Richard's colleague, Peter, looked at the same data and came up with a rather different value for the silver content in the alloy: $(92.2 \pm 1.0) \%$.

What silver mass fraction and expanded uncertainty would you assign from the given data?

We invite our readers to participate in the Analytical Challenge by solving the puzzle above. Please send the correct solution to abc-challenge@ springer.com by June 1, 2017. Make sure you enter "Measurement uncertainty challenge" in the subject line of your e-mail. The winner will be notified by e-mail, and his/her name will be published on the "Analytical and Bioanalytical Chemistry" (ABC) homepage at http:// www.springer.com/abc and in the journal (volume 409/issue 25 ), where readers will find the solution and a short explanation.

The next Analytical Challenge will be published in volume 409/issue 17, July 2017. If you have enjoyed solving this Analytical Challenge, you are invited to try the previous puzzles on the ABC homepage. 